\title{
PENERAPAN METODE AHP DAN METODE TOPSIS DALAM SISTEM PENDUKUNG KEPUTUSAN PEMILIHAN ASISTEN LABORATORIUM KOMPUTER PADA STMIK WIDYA CIPTA DHARMA SAMARINDA
}

\author{
Bartolomius Harpad $^{1)}$, Salmon ${ }^{2)}$ \\ ${ }^{1,2}$ Sistem Informasi, STMIK Widya Cipta Dharma \\ 1,2 Jl.M.Yamin No.25, Samarinda, 75123 \\ E-mail : arvenusharpad@gmail.com ${ }^{1)}$, sal.rst@gmail.com ${ }^{2)}$
}

\begin{abstract}
ABSTRAK
Penelitian pengambilan keputusan proses penerimaan asisten laboratorium yang di rancang untuk menentukan siapa saja yang akan diterima menjadi asisten laboratorium komputer. Seiring dengan perkembangan teknologi, maka pemanfaatan teknologi informasi dapat digunakan guna mempermudah dalam hal pengambilan suatu keputusan. Metode yang dipakai dalam pengambilan keputusan proses penerimaan asisten laboratorium adalah AHP (Analitical Hierarcy Process) dan Metode TOPSIS (Technique for Order Preference by Similarity to Ideal Solution). Dalam proses seleksi tersebut terdapat beberapa kriteria penilaian yang dilakukan diantaranya kemampuan mengajar, penguasaan materi, wawancara, tanggung jawab dan disiplin.
\end{abstract}

Kata Kunci: AHP, TOPSIS, Pemilihan Asisten Laboratorium

\section{PENDAHULUAN}

Pengambilan keputusan merupakan salah satu masalah yang dihadapi setiap hari. Banyak pertimbangan yang harus dipikirkan untuk mendapat keputusan yang terbaik dan terkadang banyaknya pilihan yang tersedia juga dapat membuat kita lebih sulit dalam mengambil keputusan tersebut. Seiring dengan perkembangan teknologi, maka pemanfaatan teknologi informasi dapat digunakan guna mempermudah manusia dalam hal pengambilan suatu keputusan.

Penerimaan asisten laboratorium pada Sekolah Tinggi Manajemen Informatika dan Komputer Samarinda merupakan salah satu contoh kasus dalam hal pengambilan keputusan tersebut. Laboran yang menjadi koordinator akan melakukan seleksi penerimaan asisten terhadap mahasiswa yang telah mendaftar menjadi calon asisten. Dalam proses seleksi tersebut para laboran yang dibantu oleh asisten senior biasanya melakukan wawancara dan tes kepada para calon asisten tersebut. Hasil dari wawancara maupun tes tersebut yang menjadi bahan pertimbangan para laboran untuk menentukan siapa saja yang akan diterima menjadi asisten. Akan tetapi peranan teknologi informasi sendiri terkadang hanya digunakan untuk memberikan pengumuman seputar penerimaan asisten, belum sampai digunakan pada proses pemilihan asisten tersebut.

Berdasarkan permasalahan tersebut, peranan teknologi informasi diharapkan dapat digunakan untuk membantu para laboran dalam melakukan proses penerimaan asisten laboratorium, sehingga dapat mempercepat proses dan dapat menghasilkan keputusan terbaik tentang siapa saja asisten yang diterima. Metode yang dipakai dalam pengambilan keputusan proses penerimaan asisten laboratorium adalah AHP (Analitical Hierarcy Process) dan Metode TOPSIS (Technique for Order Preference by Similarity to Ideal Solution).

Metode TOPSIS adalah salah satu metode dalam hal pengambilan keputusan multi criteria yang dapat digunakan untuk permasalahan tersebut. Metode ini dipilih karena mampu memilih alternatif terbaik dari sejumlah alternatif, dalam hal ini alternatif yang dimaksud adalah Seleksi pemilihan asisten laboratorium terbaik berdasarkan kriteria-kriteria yang ditentukan. Hasil dari proses pengimplementasian metode AHP dan TOPSIS dapat mengurutkan alternatif dari nilai yang terbesar ke nilai yang terkecil. Oleh karena itu dalam penelitian ini akan dibangun "Penerapan Metode AHP (Analitical Hierarcy Process) dan Metode TOPSIS (Technique for Order Preference by Similarity to Ideal Solution) dalam Sistem Pendukung Keputusan Pemilihan Asisten Laboratorium Komputer Pada STMIK Widya Cipta Dharma Samarinda" untuk membantu para laboran dalam hal proses penerimaan asisten. Dimana kelebihan dari metode AHP dalam mengambil suatu keputusan adalah dengan cara membandingkan secara berpasangan setiap kriteria yang dimiliki oleh suatu permasalahan sehingga didapat suatu bobot nilai dari kepentingan tiap kriteria-kriteria yang ada. 


\section{RUANG LINGKUP PENELITIAN}

\subsection{Cakupan permasalahan}

Masalahan yang ada pada penelitian ini adalah:

1. Masih kesulitan untuk menentukan calon asisten laboratorium karena hanya dengan berdasarkan satu kriteria atau atribut saja.

2. Belum adanya ketegasan dalam menentukan calon asisten laboratorium dan masih bersifat manual. Hal ini disebabkan karena para laboran belum memiliki sistem pengambilan keputusan yang berkaitan dengan pemilihan asisten laboratorium.

3. Dalam proses seleksi tersebut para laboran biasanya melakukan wawancara dan atau tes kepada para calon asisten tersebut. Hasil dari wawancara maupun tes tersebut yang menjadi bahan pertimbangan para laboran untuk menentukan siapa saja yang akan diterima menjadi asisten. Akan tetapi peranan teknologi informasi sendiri terkadang hanya digunakan untuk memberikan pengumuman seputar penerimaan asisten, belum sampai digunakan pada proses pemilihan asisten tersebut.

\subsection{Batasan-batasan penelitian}

Ruang lingkup masalah ditentukan dalam penelitian ini agar terfokus pada pokok masalah, yaitu :

1. Peranan aplikasi diharapkan dapat digunakan untuk membantu para laboran dalam melakukan proses penerimaan asisten laboratorium, sehingga dapat mempercepat proses dan dapat menghasilkan keputusan terbaik tentang siapa saja asisten yang diterima. Metode yang dipakai dalam pengambilan keputusan proses penerimaan asisten laboratorium adalah AHP (Analitical Hierarcy Process) dan Metode Topsis (Technique for Order Preference by Similarity to Ideal Solution).

2. Aplikasi dibangun berbasis Website dengan menggunakan pemrograman PHP dan database MySQL.

3. Aplikasi dan sistem yang diusulkan akan diterapkan di STMIK Widya Cipta Dharma Samarinda khususnya di bagian Laboratorium Komputer.

2.3 Rencana hasil yang didapatkan.

Ada pun tujuan pelaksanaan penelitian ini adalah :

1. Merancang SPK yang berguna untuk menyeleleksi pemilihan calon asisten laboratorium komputer di STMIK Widya Cipta Dharma Samarinda.

2. Penerapan dua metode yaitu metode AHP dan TOPSIS sebagai metode SPK.

\section{BAHAN DAN METODE}

\subsection{Penjelasan Bahan}

Tahapan Penelitian dari kerangka pemikiran umumnya memuat beberapa hal di bawah ini :

1. Rumusan Masalah (Problems) yaitu Dalam proses seleksi tersebut para laboran biasanya melakukan wawancara dan atau tes kepada para calon asisten tersebut. Hasil dari wawancara maupun tes tersebut yang menjadi bahan pertimbangan para laboran untuk menentukan siapa saja yang akan diterima menjadi asisten. Dan masih bersifat manual sehingga kesulitan untuk menentukan lulusan terbaik. Akan tetapi peranan teknologi informasi sendiri terkadang hanya digunakan untuk memberikan pengumuman seputar penerimaan asisten, belum sampai digunakan pada proses pemilihan asisten tersebut.

2. Pendekatan Masalah (Approach) dilakukan dengan menginventarisasi dan memanajemeni proses seleksi sesuai dengan kriteria yang dilengkapi dengan berbagai tes, hal ini merupakan solusi dan teori yang kita pilih dan gunakan untuk memecahkan masalah penelitian dan harus terhubung secara logis dengan masalah penelitian agar bisa membantu adanya peluang atau oportunity yang berhubungan dengan pendekatan masalah tersebut.

3. Pengembangan Perangkat Lunak (Software Development) adalah menganalisa untuk proses pengembangan software dengan desain menggunakan Flowchart dan kontruksi program perangkat lunak menggunakan PHP dan Database menggunakan MySQL.

4. Pengujian erangkat Lunak (Software Implementation) Black Box.

5. Hasil (Result) merupakan bagian yang menyimpulkan seluruh proses penelitian dan pengukuran yang telah dilakukan untuk diterapkan sebagai Sistem mengambil keputusan dalam pemilihan asisten laboratorium pada STMIK Widya Cipta Dharma Samarinda.

\subsection{Metode AHP Dan TOPSIS}

Metode AHP adalah sebagai algoritma pengambilan keputusan untuk permasalahan multikriteria (Multi Criteria Decision Making atau MCDM). Permasalahan multikriteria dalam AHP disederhanakan dalam bentuk hierarki yang terdiri dari 3 komponen utama. Yaitu tujuan atau goal dari pengambilan keputusan, kriteria penilaian dan alternatif pilihan. (Prof. Thomas L. Saaty).

Adapun langkah-langkah metode AHP adalah sebagai berikut :

1. Mendefinisikan masalah dan menentukan solusi yang diinginkan.

2. Menentukan Prioritas Kriteria :
1) Membuat Matriks Perbandingan Berpasangan
2) Membuat Matriks Nilai Kriteria
3) Membuat Matriks Penjumlahan Setiap Baris
4) Penghitungan Rasio Konsistensi

3. Menentukan Prioritas Subkriteria :

1) Membuat Matriks Perbandingan Berpasangan

2) Membuat Matriks Nilai Kriteria

3) Membuat Matriks Penjumlahan Setiap Baris

4) Penghitungan Rasio Konsistensi

Perhitungan subkriteria dilakukan terhadap sub-sub dari semua kriteria. Dalam hal ini, terdapat 5 subkriteria yang berarti akan ada 5 perhitungan prioritas subkriteria yaitu :

1. Sangat Baik

2. Baik

3. Cukup

4. Buruk

5. Sangat Buruk 
Kriteria nilai juga memiliki penilaian antara satu sampai dengan sembilan dengan ketentuan sebagai berikut:

Tabel 1. Kriteria Penilaian AHP

\begin{tabular}{|c|l|}
\hline Nilai & \multicolumn{1}{|c|}{ Keterangan } \\
\hline 1 & Sama Penting \\
\hline 2 & Mendekati sedikit lebih penting \\
\hline 3 & Sedikit lebih penting \\
\hline 4 & Mendekati lebih penting \\
\hline 5 & Lebih penting \\
\hline 6 & Mendekati sangat penting \\
\hline 7 & Sangat penting \\
\hline 8 & Mendekati mutlak \\
\hline 9 & Mutlak sangat penting \\
\hline
\end{tabular}

Metode TOPSIS adalah salah satu metode pengambilan keputusan multikriteria. Metode ini merupakan salah satu metode yang banyak digunakan untuk menyelesaikan pengambilan keputusan secara praktis. Didasarkan pada konsep dimana alternatif terpilih yang terbaik tidak hanya memiliki jarak terpendek dari solusi ideal positif, namun juga memiliki jarak terpanjang dari solusi ideal negatif (Kusumadewi, dkk).

Adapun langkah-langkah metode AHP adalah sebagai berikut :

1. Mendefinisikan masalah dan menentukan Tabel Penilaian

2. Menentukan Bobot Kriteria ( Maks 100 point )

3. Membuat matriks keputusan yang ternormalisasi

4. Membuat matriks keputusan yang ternormalisasi terbobot

5. Menentukan matriks solusi ideal positif \& matriks solusi ideal negatif

6. Menentukan jarak antara nilai setiap alternatif dengan matriks solusi ideal positif \& matriks solusi ideal negatif

7. Menentukan nilai preferensi untuk setiap alternatif

Kriteria penilaian untuk para calon asisten ini didapat berdasarkan hasil wawancara terhadap beberapa dosen yang pernah menjadi koordinator suatu matakuliah praktikum. Pemberian nilai untuk setiap calon asisten pada masing-masing kriteria, kecuali kriteria IPK dan pengalaman, dimulai dari satu sampai dengan lima dengan predikat sebagai berikut:

\section{Tabel 1. Kriteria Penilaian AHP}

\begin{tabular}{|l|l|}
\hline Nilai & Predikat \\
\hline $80-100$ & Sangat Baik \\
\hline $70-79$ & Baik \\
\hline $60-69$ & Cukup \\
\hline $40-59$ & Buruk \\
\hline $0-39$ & Sangat Buruk \\
\hline
\end{tabular}

\section{RANCANGAN SISTEM}

\subsection{Perancangan Flowchart Sistem Evaluasi Seleksi}

Perancangan sistem ini bertujuan untuk memberikan gambaran umum tentang flowchart atau diagram alir sistem untuk evaluasi seleksi yang diusulkan untuk menganalisa data calon asisten. Untuk evaluasi seleksi ini menggunakan dengan dua metode yaitu metode analytical hierarcy process dan metode Topsis seperti pada gambar 1.

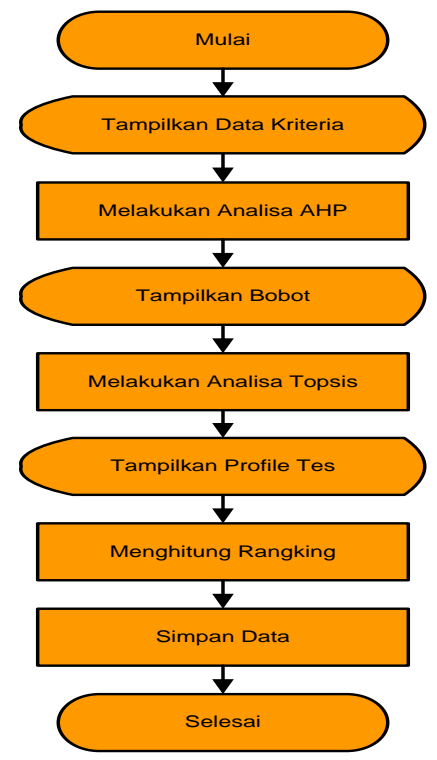

\section{Gambar 1. Perancangan Flowchart Sistem Evaluasi Seleksi}

Pada Flowchart sistem ini dimulai atau dilakukan oleh bagian administrator dimana langkah pertama administrator menampilkan data kriteria, kemudian melakukan proses analisa dengan menggunakan metode AHP, setelah itu administrator kembali menampilkan bobot dari calon asisten, langkah selanjutnya melakukan proses analisa dengan menggunakan metode TOPSIS, kemudian administrator menampilkan profil tes dari masing-masing calon asisten, kemudian bagian administrator melakukan proses tahap terakhir dengan menghitung rangking dari masing-masing calon asisten, setelah itu proses selanjutnya di simpan dalam database siapa yang layak menjadi asisten laboratorium komputer dan tahap selanjutnya proses selesai dari sistem ini.

\subsection{Perancangan Flowchart Laporan Hasil Seleksi}

Variasi Flowchart ini menggambarkan proses mencetak laporan evaluasi seleksi sehingga pimpinan dapat mengetahui dan mengambil keputusan mengenai siapa yang layak lulus seleksi atau yang lainnya.

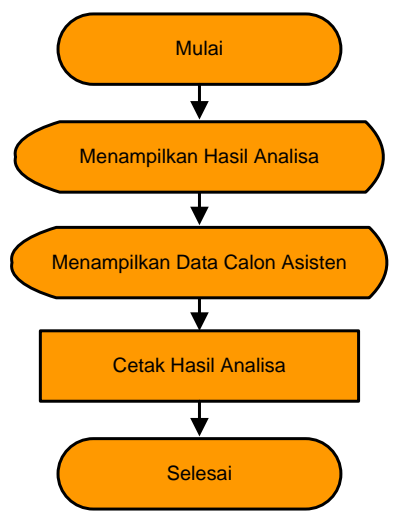

\section{Gambar 2. Perancangan Flowchart Laporan Hasil Seleksi}

Pada Flowchart ini dimulai atau dilakukan oleh bagian administrator. Pada tahap pertama admnistrator menampilkan hasil analisa dari seleksi yang telah dilaksanakan, kemudian menampilkan data calon asisten, 
setelah itu administrator melakukan proses cetak hasil analisa mengenai siapa yang layak lulus seleksi atau yang lainnya dan tahap selanjutnya proses selesai dari sistem ini.

\subsection{Struktur Tabel Penilaian}

Tabel Penilaian adalah tabel yang digunakan untuk menyimpan data penilaian.

Nama tabel

Kunci utama

$$
\begin{aligned}
& \text { : Tblpenilaian } \\
& : \text { Idcalon }
\end{aligned}
$$

Kunci tamu

Tabel 2. Tabel Penilaian

\begin{tabular}{|c|l|l|l|}
\hline Field & Tipe & Lebar & Keterangan \\
\hline idcalon & Varchar & 5 & Id Calon Asisten \\
\hline tgltes & Varchar & 25 & Tanggal Tes \\
\hline nilai1 & Int & 2 & Nilai Pertama \\
\hline nilai2 & Int & 2 & Nilai Kedua \\
\hline nilai3 & Int & 2 & Nilai Ketiga \\
\hline nilai4 & Int & 2 & Nilai Keempat \\
\hline nilai5 & Int & 2 & Nilai Kelima \\
\hline
\end{tabular}

\subsection{Tabel Hasil Hitung}

Tabel Hasil Hitung adalah tabel yang digunakan untuk menyimpan data hasil perhitungan.

$\begin{array}{ll}\text { Nama tabel } & : \text { Tblhasilhitung } \\ \text { Kunci utama } & : \text { Idcalon }\end{array}$

Kunci tamu

Tabel 2. Tabel Hasil Hitung

\begin{tabular}{|c|l|l|l|}
\hline Field & Tipe & Lebar & Keterangan \\
\hline idcalon & Varchar & 5 & Id Calon Asisten \\
\hline kriteria1 & Double & - & Kriteria Pertama \\
\hline kriteria2 & Double & - & Kriteria Kedua \\
\hline kriteria3 & Double & - & Kriteria Ketiga \\
\hline kriteria4 & Double & - & Kriteria Keempat \\
\hline kriteria5 & Double & - & Kriteria Kelima \\
\hline nilaiakhir & Double & - & Nilai Akhir \\
\hline
\end{tabular}

\section{IMPLEMENTASI}

Untuk melihat hasil dan implementasi dari penelitian ini dibangun sebuah sistem aplikasi. Aplikasi ini akan menampilkan hasil yang sudah diolah dengan menggunakan metode AHP (Analitical Hierarcy Process) dan Metode Topsis (Technique for Order Preference by Similarity to Ideal Solution).

\subsection{Halaman Utama Sistem}

Halaman utama merupakan pintu gerbang utama untuk masuk ke dalam sistem aplikasi selanjutnya. Dari sini semua aplikasi akan di mulai.

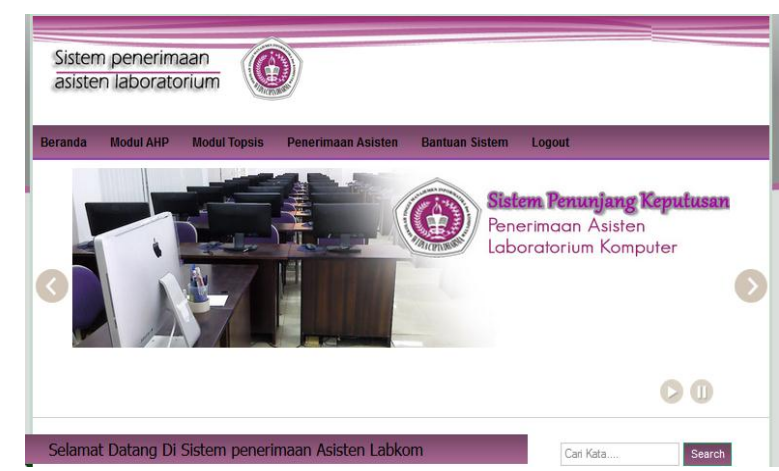

Gambar 3. Halaman Utama Sistem

Pada gambar 3, merupakan tampilan halaman utama sistem yang terdiri dari 5 (lima) menu yaitu :

1. Мепи Beranda, merupakan тепи yang berisi informasi seputar profil dan penjelasan tentang metode TOPSIS dan AHP.

2. Мепи Modul AHP, merupakan menu yang berisi proses perhitungan menggunakan metode AHP.

3. Мепи Modul TOPSIS, merupakan тепи yang berisi proses perhitungan menggunakan metode TOPSIS.

4. Мепи Penerimaan Asisten, merupakan тепи yang berisi informasi penerimaan asisten

5. Мепи Bantuan Sistem, merupakan menu yang berisi informasi cara pengunaan dan menambah login pengguna sistem.

6. Мепи Logout, merupakan mеnu untuk keluar dari sistem.

\subsection{Halaman Penerimaan Asisten}

Halaman Penerimaan Asisten yang terdiri dari: Data Calon Asisten, Tes Asisten, Proses Perhitungan Metode AHP dan Proses Perhitungan Metode TOPSIS.

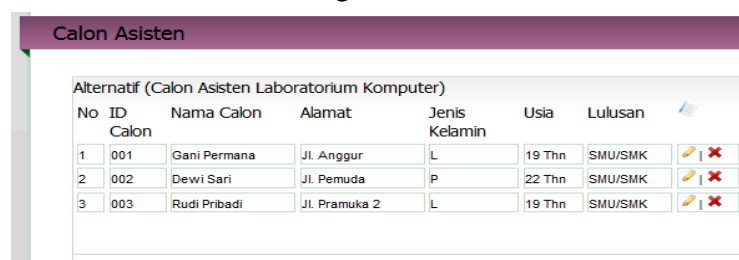

\section{Gambar 4. Form Data Calon Asisten}

Pada gambar 4 di atas, merupakan Data Calon Asisten terdiri dari: nama calon, alamat, jenis kelamin dan tanggal lahir.

Setelah itu dilakukan proses seleksi asisten dengan mengklik ulang pada kolom penilaian. Maka akan muncul proses penilaian seperti tampak pada gambar 5 .

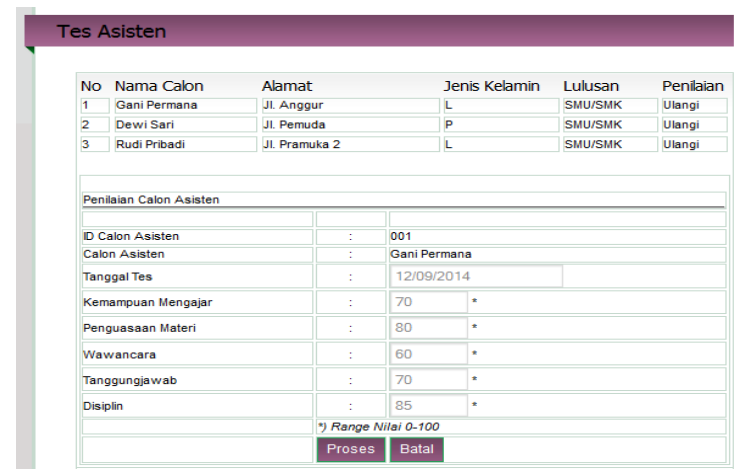

Gambar 5. Form Tes Asisten 
Pada halaman ini merupakan Form Tes Asisten yang penilaian terdiri dari: id calon asisten, nama calon asisten, tanggal tes, kemampuan mengajar, penguasaan materi, wawancara, tanggung jawab dan disiplin. Serta Range batasan penilaian antara 0-100.

Selanjutnya hasil nilai akan diproses dengan menggunakan metode AHP seperti yang tampak pada gambar 6.

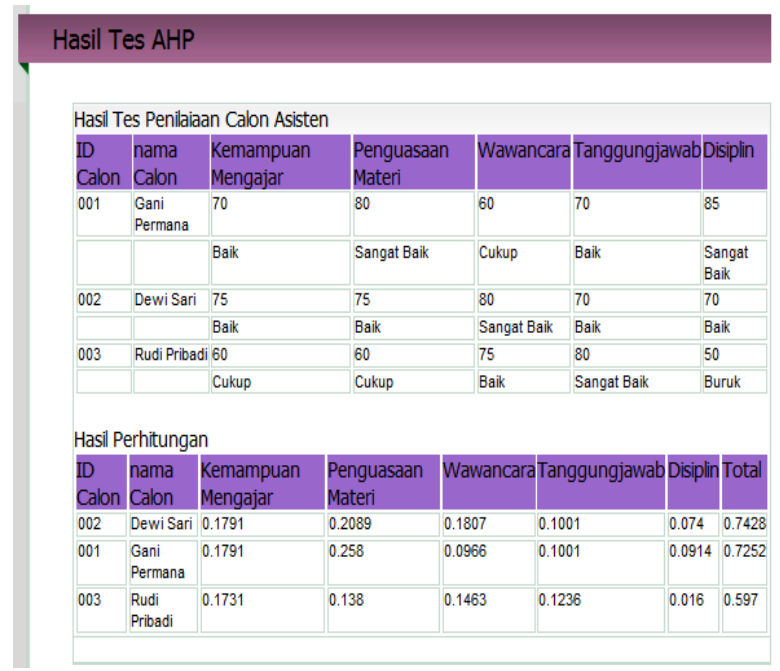

\section{Gambar 6. Hasil Tes Metode AHP}

Pada halaman ini merupakan hasil tes Asisten dimana hasil tes penilaiannya dari masing-masing kriteria berdasarkan alternatif prioritas yang sudah ditentukan. Sehingga hasil perhitungan dapat diketahui siapa yang layak untuk menjadi calon asisten laboratorium berdasarkan rangking yang diperoleh dengan menggunakan metode AHP.

Kemudian nilai diproses dengan menggunakan metode TOPSIS seperti yang tampak pada gambar 7 .

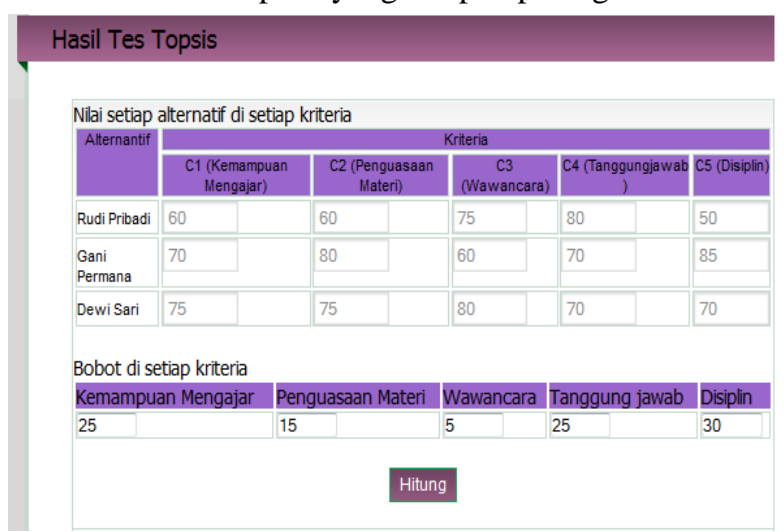

\section{Gambar 7. Nilai Alternatif Kriteria}

Pada halaman ini merupakan hasil tes Asisten dimana hasil tes penilaiannya berdasarkan kriteria dan memiliki bobot yang berbeda-beda.

Setelah itu dilakukan proses perhitungan dengan mengklik tombol hitung pada kolom penilaian TOPSIS. Maka akan muncul hasil penilaian seperti tampak pada gambar 8 .

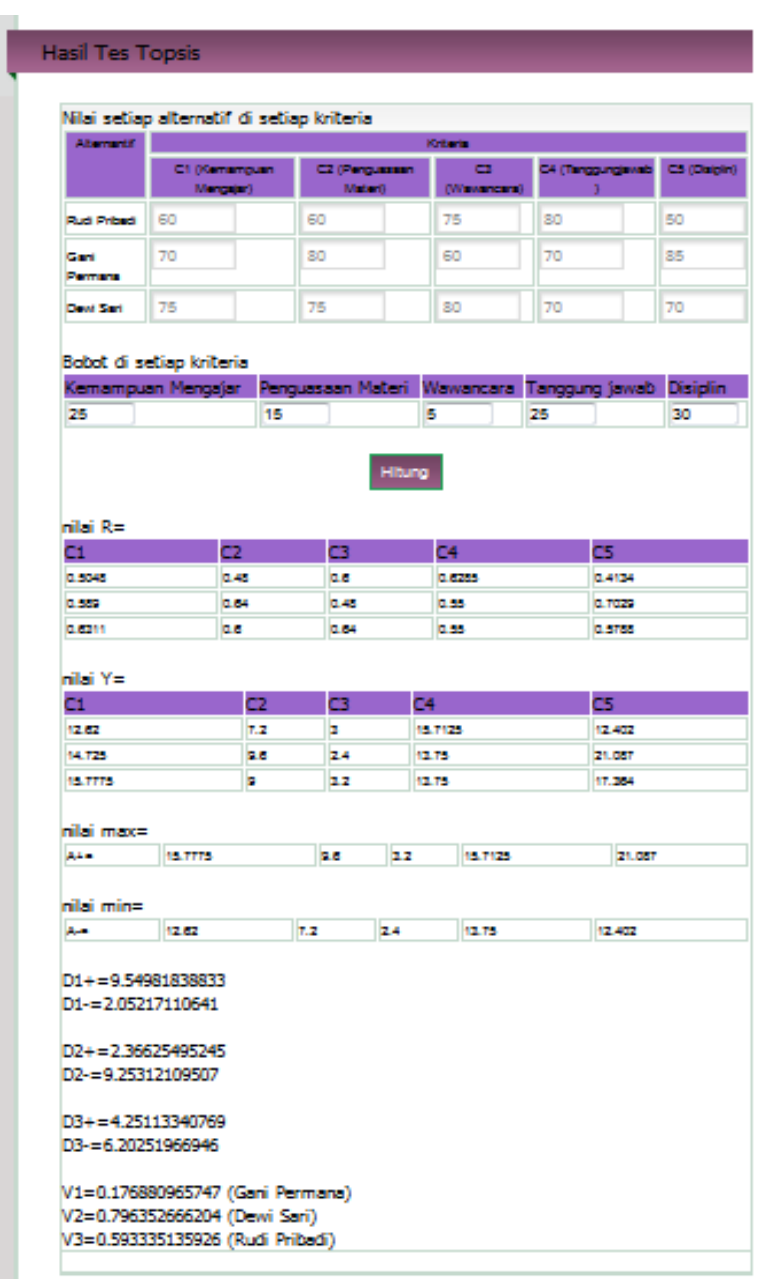

\section{Gambar 8. Hasil Tes Metode TOPSIS}

Pada halaman ini merupakan hasil tes Asisten dimana hasil tes penilaiannya berdasarkan masing-masing kriteria. Sehingga hasil perhitungan dapat diketahui siapa yang layak untuk menjadi calon asisten laboratorium berdasarkan rangking yang diperoleh dengan menggunakan metode TOPSIS.

\section{KESIMPULAN}

Berdasarkan hasil penelitian mengenai Penerapan Metode AHP dan TOPSIS dalam pemilihan Asisten Laboratorium Komputer pada STMIK WICIDA maka dapat ditarik kesimpulan sebagai berikut:

1. Penerapan pemilihan Asisten Laboratorium Komputer pada STMIK WICIDA dilakukan dengan metode AHP (Analitical Hierarcy Process) adalah sebagai berikut :

1) Pengembangan sistem pendukung keputusan pemilihan Asisten Laboratorium Komputer dimulai dengan mengkonversi nilai-nilai atribut atau kriteria-kriteria kelulusan yang paling diprioritaskan yaitu kriteria kemampuan mengajar, penguasaan materi, wawancara, tanggung jawab dan disiplin. Observasi dilakukan dengan mengamati kegiatan tes yang dilaksanakan terhadap Calon Asisten Laboratorium Komputer yang mengajukan berkas lamaran, studi dokumentasi yang menghasilkan 4 dokumen penting dalam perekrutan Asisten Laboratorium Komputer yaitu, SOP Perekrutan Asisten Laboratorium 
Komputer, kriteria perekrutan Asisten Laboratorium Komputer, berkas lamaran, formulir penilaian tes, dan hasil penilaian tes Calon Asisten Laboratorium Komputer.

2) Dalam Penerapan dimana tahapan nya dimulai dari mendefenisikan masalah dan solusi, membuat struktur hierarki, membuat matriks berpasangan, menghitung nilai eigen, dan memeriksa konsistensi hierarki hingga didapat keputusan dari alternatif yang sesuai.

2. Penerapan pemilihan Asisten Laboratorium Komputer dilakukan dengan metode TOPSIS (Technique for Order Preference by Similarity to Ideal Solution) adalah sebagai berikut :

1) Kriteria yang digunakan dalam menerapkan metode TOPSIS (Technique for Order Preference by Similarity to Ideal Solution) sama dengan kriteria yang digunakan pada metode metode AHP (Analitical Hierarcy Process), terdiri dari 5 (lima) kriteria yaitu : kriteria kemampuan mengajar, penguasaan materi, wawancara, tanggung jawab dan disiplin.

2) Metode TOPSIS (Technique for Order Preference by Similarity to Ideal Solution) didasarkan pada konsep dimana alternatif terpilih yang terbaik tidak hanya memiliki jarak terpendek dari solusi ideal positif, namun juga memiliki jarak terpanjang dari solusi ideal negatif. Langkah-langkah penyelesaian masalah yaitu : membuat matriks keputusan yang ternormalisasi, membuat matriks keputusan yang ternormalisasi terbobot, menentukan matriks solusi ideal positif \& matriks solusi ideal negatif, menentukan jarak antara nilai setiap alternatif dengan matriks solusi ideal positif \& matriks solusi ideal negatif dan Menentukan nilai preferensi untuk setiap alternatif.

\section{SARAN}

Adapun beberapa saran yang dapat diberikan kepada peneliti berikutnya apabila ingin mengembangkan sistem yang telah dibuat ini agar menjadi lebih baik adalah sebagai berikut:

1. Dapat ditambahkan data lain yang mendukung penyeleksian asisten laboratorium, misalnya penambahan kriteria.

2. Tampilan web untuk sistem yang dibuat ini masih sederhana sehingga perlu ditingkatkan lagi kualitasnya.

3. Dalam memecahkan masalah multikriteria metode AHP dan TOPSIS bukan satu-satunya penggabungan metode pengambilan keputusan yang dapat digunakan, alangkah lebih baik dicoba untuk menggunakan metode penggabungan yang lain untuk mendukung keputusan yang lebih efektif.

4. Aplikasi mendatang sebaiknya menggunakan enkripsi data atau teknologi lainnya untuk keamanan data di internet.

\section{DAFTAR PUSTAKA}

Basjir, Mochammad. 2011. Pengembangan Model Penentuan Prioritas Dan Rekomendasi Perbaikan Terhadap Mode Kegagalan Komponen Dengan Metodologi Fmea, Fuzzy Dan Topsis Yang Terintegrasi. Tesis Pasca Sarjana Teknik Industri. Institut Teknologi Sepuluh Nopember (ITS) Surabaya.

Himmah, Faiqotul. 2009. Implementasi Metode Ahp Topsis Dalam Perangkingan Prioritas Pengerjaan Order Dan Penentuan Lintasan Kritis Dengan Fuzzy Pert (Studi Kasus : PT. Meco Inoxprima). Tesis Pasca Sarjana Teknik Industri. Institut Teknologi Sepuluh Nopember (ITS) Surabaya.

Kusumadewi, dkk. 2006. Fuzzy Multi-Atribute Decision Making (MADM). Graha Ilmu. Yogyakarta.

Saaty, T.L. 2008. Science Journal Decision Making with The Analytic Hierarchy Process. Int. J. Services Sciences. Vol. 1.

Sauter, Vicki Lynn. 2010, Decision Support Systems for Business Intelligence, Second Edition. Hoboken, New Jersey. Canada : John Wiley \& Sons, Inc.

Turban, E. Aronson, J.E. dan Liang, T.P. 2005. Decision Support System And Intelligent Systems $7^{\text {th }}$ Edition. New Jersey. Prentice-Hall. Inc. 
